\title{
Dynamic Relationship Between Global Oil Price and the Eswatini's Exchange Rate: A Toda-Yamamoto Approach
}

\author{
Sotja G. Dlamini \\ Department of Agricultural Economics and Management, University of Eswatini, Luyengo, Eswatini
}

\begin{abstract}
Globalization and liberalization puts the emphasis on exports as a technique in which developing countries like the Kingdom of Eswatini should adopt to expand their markets beyond their domestic market. For the developing countries to be international competitive in the global markets they need to minimize their production cost particularly on the products that are being exported. The production of most of the exported commodities needs lot energy from oil; hence there has been tremendous increase of oil and its by-product worldwide. The current oil demand for most countries in the world is not met because of insufficient reserves for crude oil in most countries. The Kingdom of Eswatini does not have an oil reserves or oil-refining facilities hence they depends on imports from the neighbouring states in order to meet the consumption requirement. The oil price shocks in the global market normally have adversely effects on various macroeconomic variables such as exchange rate since the oil is traded in US dollars. Oil and exchange rate are considered to be essential factors for domestic economies for developing countries like the Kingdom of Eswatini. The purpose of the study is to investigate the causal relationship between Lilangeni-dollar exchange rate and crude oil price by using the Toda-Yamamota approach. The study used daily time series from January 01st, 2005 to April 30th, 2018 of nominal exchange rate of Lilangeni (Eswatini currency [SZL]) vis-à-vis United States dollar (USD) data as well as the global price of Brent crude oil data that was used as a proxy for the Global crude oil price. The results from the Toda-Yamamoto Granger causality test revealed that there is a unidirectional causality from the global oil price to the Eswatini's nominal exchange rate (SZL/USD). Hence the study concluded that the global crude oil price influence the Eswatini's nominal exchange rate. Therefore the study recommends that in the formulating of Eswatini's exchange rate policy emphases should be on the global oil prices in order not to misalign the Eswatini's currency.
\end{abstract}

Keywords: Toda-yamamota; Crude oil; Exchange rate; Macroeconomic; Eswatini.

(9) (9) CC BY: Creative Commons Attribution License 4.0

\section{Introduction}

Developing countries like the Kingdom of Eswatini is not lacking behind the era of liberalization and globalization that puts the emphasis on exports as a technique in which these countries should adopt to expand their markets beyond their domestic market. For the developing countries to be international competitive in the global markets they need to minimize their production cost particularly on the products that are being exported (Ustaoglu and Yildiz, 2011). Kaygusuz (2007), stated that there is a significant economic development in those countries that uses oil as a source of energy in their production of commodities; hence the need of oil and its by-product has increased tremendous worldwide. The current oil demand for most countries in the world is not met because of insufficient reserves for crude oil in most countries. Therefore, countries imports the oil and its by-product from those countries that are in abundance and those who are selling this commodity are paid in US dollars due to the power that the US currency has in determining the price in the international market.

The Kingdom of Eswatini does not have an oil reserves or oil-refining facilities hence they depends on imports from the neighbouring states in order to meet the consumption requirement. The petroleum products that are consumed in the Kingdom of Eswatini are imported, mostly from the South African Durban refineries and occasionally from Mozambique. According to Nkomo (2009), there is no commercial oil reserve that is found in South Africa and the only activity that is done in that country is the refinery of the crude oil that is being imported. The dependence on the imported crude oil exposes South Africa and its trading partners like Eswatini to disorders that can cause the oil prices to increase that have a negative bearing on the development and economic growth of the countries. According to Hussain et al. (2015), the crude oil price per barrel was over $\$ 140$ by June 2008 and it went down to $\$ 110$ per barrel by mid 2014 and drop significantly to $\$ 46$ per barrel in the early 2015 . The main factor that had contributed to the crude oil price drop was the discovery of the oil reserve in North Dakota and Texas during this period that had increased the quantity of oil being supplied in the world market hence leads to the flooding the international market with their oil supply. The oil price shocks in the global market normally have adversely effects on various macroeconomic variables such as exchange rate since the oil is traded in US dollars. Oil and exchange rate are considered to be essential factors for domestic economies for developing countries like the Kingdom of Eswatini, therefore through the use of Toda-Yamamota approach the objective of the paper is to investigate the causal relationship between Lilangeni-dollar exchange rate and crude oil price. The current study contributes by filling the knowledge gap in literature as well as providing evidence-based policies on energy and exchange rate that can be adopted by the Kingdom of Eswatini to stimulate economic growth. To the best knowledge of the author, 
there is no study in literature that has been carried before in the Kingdom of Eswatini on this topic. The remainder of the paper is organized as follows. Section 2 provides a review of the empirical literature for related studies. Section 3 describes the methodology used. Section 4 presents and interprets the empirical results, while conclusions and policy implications are presented in section 5 .

\section{Literature Review}

The dynamics relationship between oil price and exchange rate is build on the theoretical framework that was built by Krugman (1983) and Golub (1983), that explains that the relationship between the two variables is through wealth transfer and international portfolio preferences. The increases in the oil prices will induce a transfer of wealth from the countries that are importing oil to the countries that are exporting oil, hence depleting the reserves of the foreign currency in the current account of the importing countries leading to its currency depreciating. The transfer of wealth by the oil importing countries is a short-run phenomenon because those countries have to adjust since this leads to inflation and depreciation of the domestic currency. In the international portfolio preferences the focuses is on the investment decisions by the oil exporting countries. The increase in the oil price extends impacts from medium to long-term period due to wealth that is being received by these countries that improves the balances of the current account in those countries causing a decrease in exchange rate. The differentiated exchange rate among the countries is due to the wealth reallocation that is being caused by the import preferences.

Sharma et al. (2017), conducted a study in India to analyze the dynamic relationship between crude oil price and exchange rate using the Toda and Yamamoto Approach. The study used daily time series from 16 February 2015 to 01 February 2018. The outcome of the study indicated that there was a unidirectional causality from the price of crude oil to the rupee dollar exchange rate.

Benhabib et al. (2014), conducted a study in Algeria to investigate the connection between the nominal exchange rate and oil price. The study used monthly data from 2003 to 2013 and a co-integration and Vector Autoregressive (VAR) model were employed to analyze the data. The outcomes of the analysis discovered that the Algerian currency depreciation was caused by the increase in the oil prices.

Reboredo and Castro (2013), conducted a study to check for the crisis presence before 2008 between the price of oil and exchange rate by employing wavelet decomposition model. Daily data for these two variables were used from 200 to 211 . The findings revealed that before 2008 there was no relationship between the price of oil and the exchange rate, but after 2008 there was bidirectional causality between the oil price and the exchange rate.

Tiwari et al. (2013), investigated the relationship between the international oil price and fluctuations of the real exchange rate in Romania. The study employed a Granger causality test as well as the transformed wavelet network model. The dataset that was used by the study was from February 1986 to March 2009 for the two variables of interest. The outcomes of the study revealed that both in the short run and long run the increase in the prices of oil lead to the appreciation of the Romanian currency.

Adiguzel et al. (2013), conducted a study to check on the dynamic relationships between real oil price and real exchange rate of dollar in Brazil, India and Turkey. The period that was covered for Brazil was from January1999 to July 2011, while for India the period that was covered was from March 1993 to July 2011, and for Turkey the period that covered was from February 2001 to July 2011. The method that was included the linear and nonlinear Granger causality, volatility spillover, as well as the frequency domain causality tests. The results from using the frequency domain test revealed that for all the countries there is a short run causality relationship from the real exchange rate to real oil price, but in India for both short and long run there is bidirectional causality between this variables.

Turhan et al. (2012), inspected the dynamics between exchange rate of selected emerging countries and prices of oil. The study used daily data for the two variables. The results from the study indicated the increase in the price of oil lead to the substantial currency appreciation for the emerging countries against the US dollar. The generalized impulse response functions were employed to find the impact on three different times. The findings showed that oil price dynamics impact on exchange rate changes over time and the impact was more pronounced after the 2008 financial crises.

Based on the literature that was reviewed most of the studies were testing the causality between the price of crude oil and exchange rate using the conventional Granger (1969) causality test, hence this study point of departure is that it applies the innovative causality test proposed by Toda Yamamota approach known as modified Wald test (MWALD) as suggested by Dolado and Lutkepohl (1996). Therefore, this is the gap this study intends to fill. The Toda-Yamamoto approach that was used by the study has been found to be superior to the ordinary Grangercausality tests since it eliminates the need for pre-testing for co-integration hence avoiding pre-test bias as well as minimising the risks associated with the possibility of wrongly identifying the order of integration of the series through the use of fitted vector autoregressive model (Mavrotas and Kelly, 2001).

\section{Materials and Methods \\ 3.1. Data Type and Sources}

In order to carry out the objectives of the study daily time series from January $01^{\text {st }}, 2005$ to April $30^{\text {th }}, 2018$ of nominal exchange rate of Lilangeni (Eswatini currency [SZL]) vis-à-vis United States dollar (USD) data and the global price of Brent crude oil data that was used as a proxy for the Global crude oil price. The data for the nominal exchange were sourced from the Central Bank of Eswatini and the global crude oil price data was sourced from the US Energy Information Administration (http://www.eia.doe.gov/dnav/pet/TblDefs/pet_pri_spt tbldef2.asp). The time series were transformed into natural $\log$ before it was used. 


\subsection{Model Specification}

The purpose of this study was to examine the dynamic relationship between the global crude oil price and the Eswatini's Exchange rate using Toda-Yamamota granger causality approach. As stated in the literature review the Toda-Yamamota approach of determining causality among variables is superior compared to the other traditional granger causality methods because the granger causality test using the Toda-Yamamoto approach can provide valid results even if it is applied to non-stationary series as long as the maximal order of the integration of the series is added into the model. The Toda-Yamamoto Granger causality test between the two variables of the study was estimated through the following bivariate Vector Autoregression [VAR] Model:

$$
\begin{aligned}
& C_{i}=a_{0}+\sum_{i=1}^{k+m} a_{i} C_{t-i}+\sum_{j=1}^{k+m} b_{i} E_{t-j}+\mu_{i t} \\
& E_{i}=c_{0}+\sum_{i=1}^{k+m} c_{i} E_{t-i}+\sum_{j=1}^{k+m} d_{i} C_{t-j}+v_{i t}
\end{aligned}
$$

Where $\mathrm{C}$ is the global oil price, $\mathrm{E}$ is the Exchange rate between Eswatini's currency and USD; $\mathrm{m}$ is the maximal order of integration order of the variables in the system. In order to test for the order of integration the PhillipsPerron (PP) and the augmented Dickey-Fuller (ADF) unit root test that was proposed by Dickey and Fuller were used by the study. Then in order to obtain the optimum lag length $(\mathrm{k})$ among the variables in the VAR system model different lag length criterions were used such as the Akaike information criterion (AIC), Schwarz information criterion (SC), final prediction error (FPE) and Hannan Quinn (HQ) information criterion. Then $\mu_{\mathrm{it}}$ and $v_{\mathrm{it}}$ are the error terms that are assumed to be white noise with zero mean, constant variance and not autocorrelation. Then the inferences on the Granger causality was conducted by applying the Wald test on the model and linear restrict all the first lagged values on equation 1 and 2 . Then the null hypothesis that can be drawn for the first equation $\mathrm{E}$ does not Granger-cause $\mathrm{C}$ is represented as:

$$
H_{0}: \sum_{j=1}^{k} b_{i}=0 ; H_{1}: \sum_{j=1}^{k} b_{i} \neq 0
$$

And for the second equation the null hypothesis that $\mathrm{C}$ does not Granger-cause $\mathrm{E}$ is represented as:

$$
H_{0}: \sum_{j=1}^{k} d_{i}=0 ; H_{1}: \sum_{j=1}^{k} d_{i} \neq 0
$$

The null hypothesis on the Wald test statistics has an asymptotic chi-square distribution and there are three outcomes that can be achieved; unidirectional causality will occur between

two variables if either null hypothesis of equation (1) or (2) is rejected; Bidirectional causality exists if both null hypotheses are rejected; Independent causality exists under the null hypothesis of equation (1) nor (2) is rejected.

\section{Results and Discussion}

In order to avoid spurious causality or spurious absence of causality the study checked for the order integration among the variables by using both ADF and PP unit root test and the maximal order of integration between the two variables were used by the Toda-Yamamota approach. The results are presented in Table 1 for both ADF and PP respectively. The results of the test statistics revealed that both variables are non-stationary at their levels but stationary at their first differences, being integrated of order one, I (1). Therefore, the maximum order of integration for the variables in the system is one $(\mathrm{d}=1)$.

Table-1. Unit Root Tests

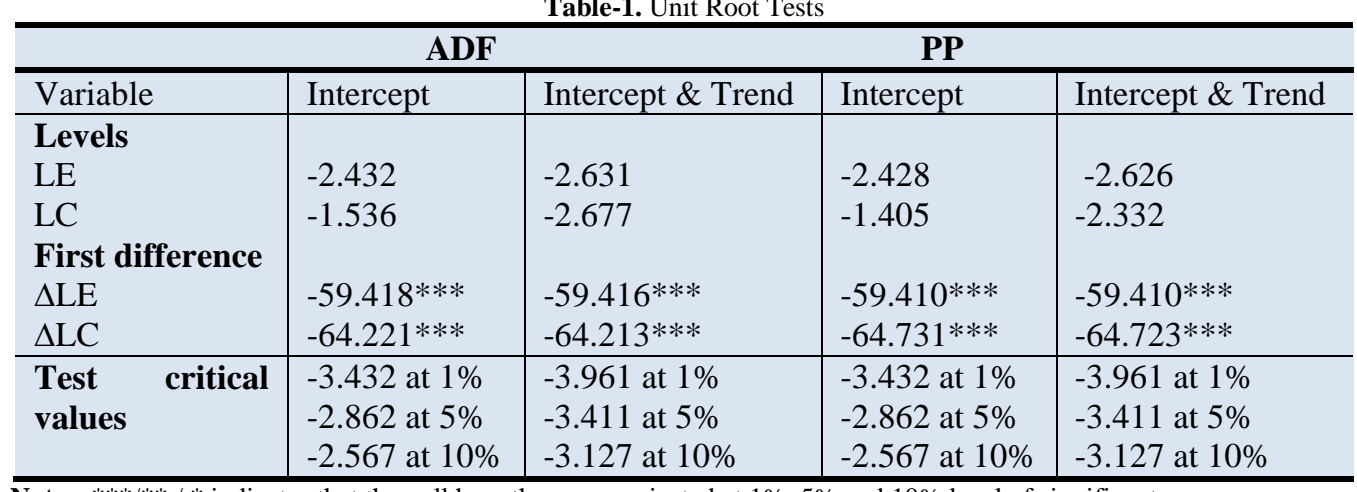

Notes: $* * * * * / *$ indicates that the null hypotheses are rejected at $1 \%, 5 \%$ and $10 \%$ level of significant.

Source: Author's calculation using Eviews software, version 10.

The next step after identifying the maximal order of integration is to select the optimal lag length $(\mathrm{k})$ since if it under fitted it will leads VAR model to have a problem of autocorrelation. AIC, FPE, SC and HQ were used to choose the lag length. Based on the results that are presented on Table 2 the optimal lag length for variables in the system is two $(\mathrm{k}=2)$ out of a maximum of 8 lag lengths as selected by AIC, SC, HQ and FPE. 
International Journal of World Policy and Development Studies

Table-2. Lag Length Selection

\begin{tabular}{l|l|l|l|l}
\hline Lag & AIC & SC & HQ & FPE \\
\hline 0 & 0.556985 & 0.560642 & 0.558293 & 0.005983 \\
1 & -10.70274 & -10.69177 & -10.69882 & 7.71 \\
2 & $-10.71021^{*}$ & $-10.69193^{*}$ & $-10.70367^{*}$ & $7.65 *$ \\
3 & -10.70803 & -10.68243 & -10.69887 & 7.67 \\
4 & -10.70771 & -10.67481 & -10.69594 & 7.67 \\
5 & -10.70578 & -10.66556 & -10.69140 & 7.68 \\
6 & -10.70769 & -10.66016 & -10.69069 & 7.67 \\
7 & -10.70560 & -10.65075 & -10.68598 & 7.69 \\
8 & -10.70615 & -10.64399 & -10.68392 & 7.68 \\
\hline
\end{tabular}

Notes: * indicates lag order selection by the criterion.

Once the order of integration and the optimal lag selection was achieved, we then undertake the TodaYamamota granger causality test, for VAR (3), ( $\mathrm{d}=1$ and $\mathrm{k}=2)$, we estimated the system equation 1 and 2 and then test the hypothesis of the estimates through MWALD test that follows the chi-square distribution with 3 degree of freedoms in accordance with the appropriate lag length and associated probability as presented in Table 3.

Table-3. Toda-Yamamoto test of Granger Causality

\begin{tabular}{l|l|l|l}
\hline Null Hypothesis & MWald & Df & Prob \\
\hline $\mathrm{H}_{0}$ : LE does not Granger-cause LC & 4.255 & 2 & 0.119 \\
$\mathrm{H}_{0}$ : LC does not Granger-cause LE & 6.442 & 2 & $0.039 * *$ \\
\hline Note: ***,*** indicates statistical significance at the 1\%, 5\%, and $10 \%$ level of \\
significance respectively. \\
Source: Author's calculation using Eviews software, version 10
\end{tabular}

The results on the granger causality in Table 3 revealed that there is one-way causality from the global oil price to the Eswatini's nominal exchange rate (SZL/USD) with a significance level of 5\%, suggesting that there is a unidirectional causality from global oil price to the nominal exchange in the Kingdom of Eswatini. The monopolistic determination of the price of oil as well as its pricing based in United States of America dollar is cited as one the reason for the one-way causality. The fluctuation of the oil price will turn to influence the US dollars to appreciate (or depreciate) and its counter impact is reflected on the Eswatini's currency exchange rate to the dollar. The results are consistent with the outcome from the studies that was carried by Brahmasrene et al. (2014); Sharma et al. (2017) that also concluded that there is unidirectional causality running from international crude oil prices to the nominal exchange rate in United States of America and India respectively.

\section{Summary and Conclusions}

The main objective of this study was to examine the dynamic relationship between the global crude oil price and the Eswatini's Exchange rate using Toda-Yamamota granger causality approach, which is considered to be one of the superior Granger- causality tests since it eliminates the need for pre-testing for cointegration and therefore avoids pre-test bias and is applicable for any arbitrary level of integration for the series used. The data used in this study were daily time series from January $01^{\text {st }}, 2005$ to April $30^{\text {th }}, 2018$ of nominal exchange rate of Lilangeni (Eswatini currency [SZL]) vis-à-vis United States dollar (USD) and the global price of Brent crude oil data that was used as a proxy for the Global crude oil price. The study applied a bivariate vector autoregressive (VAR) model that involves diagnoses test for the unit root, optimal lag selection before applying the Granger causality test on the variables.

The empirical results from the Toda-Yamamoto Granger causality test revealed that there is a unidirectional causality from the global oil price to the Eswatini's nominal exchange rate (SZL/USD). Hence the study concluded that the global crude oil price influence the Eswatini's nominal exchange rate. Therefore the study recommends that government or policy makers should consider the oil prices in the global market when they are formulating their exchange rate policy in order not to cause a misalignment in the Lilangeni.

\section{References}

Adiguzel, U., Bayat, T., Kayhan, S. and Nazlioglu, S. (2013). Oil price and exchange rates in brazil, india and turkey: Time and frequency domain causality analysis. Research journal of politics, economics and management, sakarya university. Faculty of Economics and Administrative Sciences, 1(1): 49-73.

Benhabib, A., Si Mohammed, K. and Maliki, S. (2014). The relationship between oil price and the algerian exchange rate. Topics in Middle Eastern and African Economies, 16(1): 127-41.

Brahmasrene, T., Huang, J. and Sissoko, Y. (2014). Crude oil prices and exchange rates: Causality, variance decomposition and impulse response. Energy Economics, 44(2014): 407-12.

Dolado, J. J. and Lutkepohl, H. (1996). Making wald test work for cointegrated var system. Econometric Reviews, 15(4): 369-86.

Golub, S. S. (1983). Oil prices and exchange rates. The Economic Journal, 93(371): 576-93.

Granger, C. W. J. (1969). Investigating causal relations by econometric models and cross-spectral methods. Econometrica, 37(3): 424-38. 
Hussain, A. M., Arezki, R., Breuer, P., Haksar, V., Helbling, T., Medas, P. and Sommer, M. (2015). Global implications of lower oil prices. Staff discussion notes no. 15/15. IMF Staff Discussion Notes, 15(2015): 41.

Kaygusuz, K. (2007). Energy for sustainable development: Key issues and challenges. Energy sources, Part B: Economics, Planning, and Policy, 2(1): 73-83.

Krugman, P. (1983). Oil and the dollar. In: Bhandari, J.S. Putnam, B.H. economic interdependence and flexible exchangerates. Cambridge University Press: Cambridge.

Mavrotas, G. and Kelly, R. (2001). Old wine in new bottles: Testing causality between savings and growth. The Manchester School, 69(1): 97-105.

Nkomo, J. (2009). Energy security and liquid fuels in South Africa. Journal of Energy in Southern Africa, 20(1): 2024.

Reboredo, J. and Castro, M. (2013). A wavelet decomposition approach to crude oil price and exchange rate dependence. Economic Modelling, 32(2013): 42-57.

Sharma, A., Rishad, A. and Kumar, V. (2017). Crude oil prices and exchange rate in india: Evidence from toda and yamamota approach. Journal of economics and Business Research, 23(2): 7-30.

Tiwari, A., Kumar, M. M. and Claudiu, T. A. (2013). The influence of the international oil prices on the real effective exchange rate in Romania in a wavelet transform framework. Energy Economics 40(2013): 714 33.

Turhan, I., Hacihasanoglu, E. and Soytas, U. (2012). Oil prices and emerging market exchange rates. Emerging Markets Finance and Trade, 49(1): 21-36.

Ustaoglu, M. and Yildiz, B., 2011. "Information technology's effect on Turkey's foreign trade: An investigation for the last decade." In 7th International Strategic Management Conference, Paris. 